\title{
Atrial fibrillation complicating lung cancer resection
}

\author{
Eric E. Roselli, MD, ${ }^{a}$ Sudish C. Murthy, MD, PhD, ${ }^{a}$ Thomas W. Rice, MD, ${ }^{a}$ Penny L. Houghtaling, MS, \\ Christopher D. Pierce, PhD, ${ }^{b}$ Daniel P. Karchmer, MBA, ${ }^{a}$ and Eugene H. Blackstone, MD ${ }^{a, b}$
}

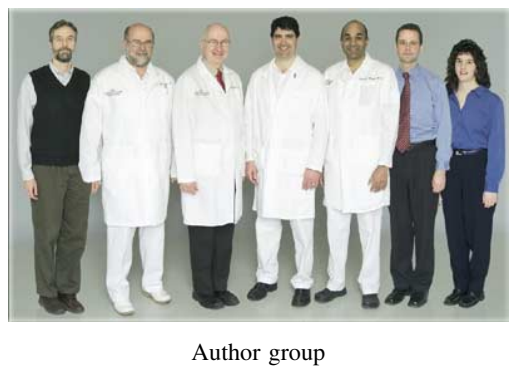

Further material is available online. 角
From the Departments of Thoracic and Cardiovascular Surgery ${ }^{\mathrm{a}}$ and Quantitative Health Sciences ${ }^{\mathrm{b}}$, The Cleveland Clinic Foundation, Cleveland, Ohio.

Received for publication Oct 27, 2004; revisions received Jan 24, 2005; accepted for publication Feb 10, 2005.

Address for reprints: Sudish C. Murthy, $\mathrm{MD}, \mathrm{PhD}$, The Cleveland Clinic Foundation, 9500 Euclid Ave, Desk F24, Cleveland, OH 44195 (E-mail: murthys1@ccf. org).

J Thorac Cardiovasc Surg 2005;130:438-44

$0022-5223 / \$ 30.00$

Copyright (c) 2005 by The American Association for Thoracic Surgery

doi:10.1016/j.jtcvs.2005.02.010
Objective: To (1) characterize atrial fibrillation complicating lung cancer resection, (2) evaluate its temporal relationship to other postoperative complications, and (3) assess its economics.

Methods: From January 1998 to August 2002, 604 patients underwent anatomic lung cancer resection. Atrial fibrillation prevalence, onset, and temporal associations with other postoperative complications were determined. Propensity matching was used to assess economics.

Results: Atrial fibrillation occurred in 113 patients (19\%), peaking on postoperative day 2. Older age, male gender, heart failure, clamshell incision, and right pneumonectomy were risk factors $(P<.01)$. Although atrial fibrillation was solitary in 75 patients $(66 \%)$, other postoperative complications occurred in 38. Respiratory and infectious complications were temporally linked with atrial fibrillation onset. In 91 propensity-matched pairs, patients developing atrial fibrillation had more other postoperative complications (30\% vs. $9 \%, P<.0004)$, had longer postoperative stays (median 8 vs 5 days, $P<.0001$ ), incurred higher costs (cost ratio 1.8, 68\% confidence limits 1.6-2.1), and had higher in-hospital mortality ( $8 \%$ vs $0 \%, P=$ $.01)$. Even when atrial fibrillation was a solitary complication, hospital stay was longer (median 7 vs 5 days, $P<.0001$ ), and cost was higher (cost ratio $1.5,68 \%$ confidence limits 1.2-1.6).

Conclusion: Atrial fibrillation occurs in 1 in 5 patients after lung cancer resection, with peak onset on postoperative day 2. Risk factors are both patient and procedure related, and atrial fibrillation may herald other serious complications. Although often solitary, atrial fibrillation is associated with longer hospital stay and higher cost. It therefore requires prompt treatment and should stimulate investigation for other problems.

$\Lambda$ trial fibrillation (AF) commonly complicates pulmonary resection. ${ }^{1-14} \mathrm{Al}-$ though $\mathrm{AF}$ is medically manageable, its impact on recovery and economics is unclear. $^{6-8,15}$ We hypothesized that it might herald poor outcome, and we therefore (1) characterized AF complicating lung cancer resection, (2) evaluated its temporal relation to other postoperative complications, and (3) assessed its economics.

\section{Patients and Methods \\ Patients}

Between January 1998 and August 2002, 625 consecutive patients undergoing anatomic resection for non-small cell lung cancer at The Cleveland Clinic Foundation were identified from the Thoracic Surgery Database. Of these, 21 were excluded because they had permanent AF $(n=13)$, previous lung transplantation $(n=1)$, previous lung resection $(n=4)$, or incomplete records $(n=3) .{ }^{15}$ Patients who had a history of paroxysmal AF but were in sinus rhythm at operation were included. Thus, 604 patients were studied (Table 1). The Thoracic Surgery Database has been approved for use in research by the institutional review board. 
TABLE 1. Patient and operative characteristics

\begin{tabular}{|c|c|c|c|c|}
\hline \multirow[b]{2}{*}{ Variable } & \multirow[b]{2}{*}{ Total $(n=604)$} & \multicolumn{2}{|c|}{ Postoperative AF } & \multirow[b]{2}{*}{$P$ value* } \\
\hline & & Yes $(n=113)$ & No $(n=491)$ & \\
\hline \multicolumn{5}{|l|}{ Demographic } \\
\hline Male (No.) & $352(58 \%)$ & $85(75 \%)$ & $267(54 \%)$ & $<.0001$ \\
\hline Age $(y$, mean $\pm S D)$ & $64 \pm 11$ & $68 \pm 8.0$ & $63 \pm 12$ & $<.0001$ \\
\hline \multicolumn{5}{|l|}{ Cardiovascular comorbidity (No.) } \\
\hline History of paroxysmal AF & $32(5 \%)$ & $18(16 \%)$ & $14(3 \%)$ & $<.0001$ \\
\hline History of ventricular arrhythmia & $5 / 597(1 \%) \dagger$ & $2 / 112(2 \%)$ & $3 / 485(0.6 \%)$ & .2 \\
\hline Coronary artery disease & $112 / 548(19 \%)$ & $37 / 112(33 \%)$ & $75 / 486(15 \%)$ & $<.0001$ \\
\hline Mitral valve disease & $14 / 547(2 \%)$ & $5 / 112(4 \%)$ & $9 / 485(2 \%)$ & .15 \\
\hline Heart failure & $22 / 547(4 \%)$ & $13 / 112(12 \%)$ & $9 / 485(2 \%)$ & $<.0001$ \\
\hline History of pulmonary embolism & $4 / 597(1 \%)$ & $2 / 112(2 \%)$ & $2 / 485(0.4 \%)$ & .16 \\
\hline Hypertension & $93 / 547(16 \%)$ & $32 / 112(28 \%)$ & $61 / 485(13 \%)$ & $<.0001$ \\
\hline Previous cardiac operation & $56(9 \%)$ & $17(15 \%)$ & $39(8 \%)$ & .02 \\
\hline \multicolumn{5}{|l|}{ Noncardiac comorbidity (No.) } \\
\hline Smoking & $521 / 536(97 \%)$ & $103 / 107(96 \%)$ & $418 / 429(97 \%)$ & .5 \\
\hline Previous thoracotomy & $2(0.3 \%)$ & $2(2 \%)$ & $0(0 \%)$ & .03 \\
\hline Hyperthyroidism & $1 / 597(0.2 \%)$ & $0 / 112(0 \%)$ & $1 / 485(0.2 \%)$ & 1.0 \\
\hline ECOG score & & & & .08 \\
\hline 0 & $287(48 \%)$ & $44(39 \%)$ & $243(50 \%)$ & \\
\hline 1 & $243(41 \%)$ & $52(46 \%)$ & $191(39 \%)$ & \\
\hline 2 & $63(10.5 \%)$ & $17(15 \%)$ & $46(9 \%)$ & \\
\hline 3 & $3(0.5 \%)$ & $0(0 \%)$ & $3(1 \%)$ & \\
\hline Not recorded & 8 & 0 & 8 & \\
\hline \multicolumn{5}{|l|}{ Procedure (No.) } \\
\hline \multicolumn{5}{|l|}{ Approach } \\
\hline Thoracotomy & $596(99 \%)$ & $110(97 \%)$ & $486(99 \%)$ & 1.0 \\
\hline Clamshell incision & $4(0.7 \%)$ & $3(3 \%)$ & $1(0.2 \%)$ & .02 \\
\hline Sternotomy & $4(0.7 \%)$ & $0(0 \%)$ & $4(0.8 \%)$ & 1.0 \\
\hline \multicolumn{5}{|l|}{ Anatomic resection } \\
\hline Pneumonectomy & $85(14 \%)$ & $24(21 \%)$ & $61(12 \%)$ & .01 \\
\hline Right & $37(6 \%)$ & $15(13 \%)$ & $22(4 \%)$ & .0004 \\
\hline Left & $48(8 \%)$ & $9(8 \%)$ & $39(8 \%)$ & .99 \\
\hline Intrapericardial & $15(2 \%)$ & $4(4 \%)$ & $11(2 \%)$ & .5 \\
\hline Lobectomy & $474(78 \%)$ & $81(72 \%)$ & $393(80 \%)$ & .05 \\
\hline Segmentectomy & $48(8 \%)$ & $9(8 \%)$ & $39(8 \%) \ddagger$ & .99 \\
\hline \multicolumn{5}{|l|}{ Additional procedures (No.) } \\
\hline Wedge resection & $44(7 \%)$ & $5(4 \%)$ & $39(8 \%)$ & .2 \\
\hline Sleeve resection & $20(3 \%)$ & $6(5 \%)$ & $14(3 \%)$ & .2 \\
\hline Mediastinal lymph node dissection & $310(51 \%)$ & $55(49 \%)$ & $255(52 \%)$ & .5 \\
\hline Chest wall resection & $28(5 \%)$ & $4(4 \%)$ & $24(5 \%)$ & .5 \\
\hline
\end{tabular}

$A F$, Atrial fibrillation; ECOG, Eastern Cooperative Oncology Group; SD, standard deviation. *Test of difference between AF and non-AF groups; Fisher's exact test used where appropriate. $†$ Denominator represents number of patients without missing data. $\ddagger$ One patient had lobectomy and segmentectomy.

\section{Surgical Technique and Patient Management}

Resection was universally completed extrapericardially, with intrapericardial resection rescored for those cases listed as such (Table E1). All preoperative medications were resumed when enteral feedings were begun (usually postoperative day 1). No attempt was made to provide prophylaxis against the development of $\mathrm{AF}$.

\section{Postoperative AF}

All patients had heart rhythm telemetry throughout their hospital stay. Postoperative AF was defined as electrocardiographically demonstrated AF requiring treatment. Interval to AF was calculated from time of incision.

\section{Other Postoperative Complications}

Other hospital complications were categorized as respiratory, infectious, pleural, renal, and other cardiovascular (Appendix 1). Interval for each was calculated from onset of AF; complications were then categorized as preceding onset of AF (between incision and 12 hours before onset of AF), coincident with AF (within 12 hours before or after), or after onset of AF (more than 12 hours after AF). 

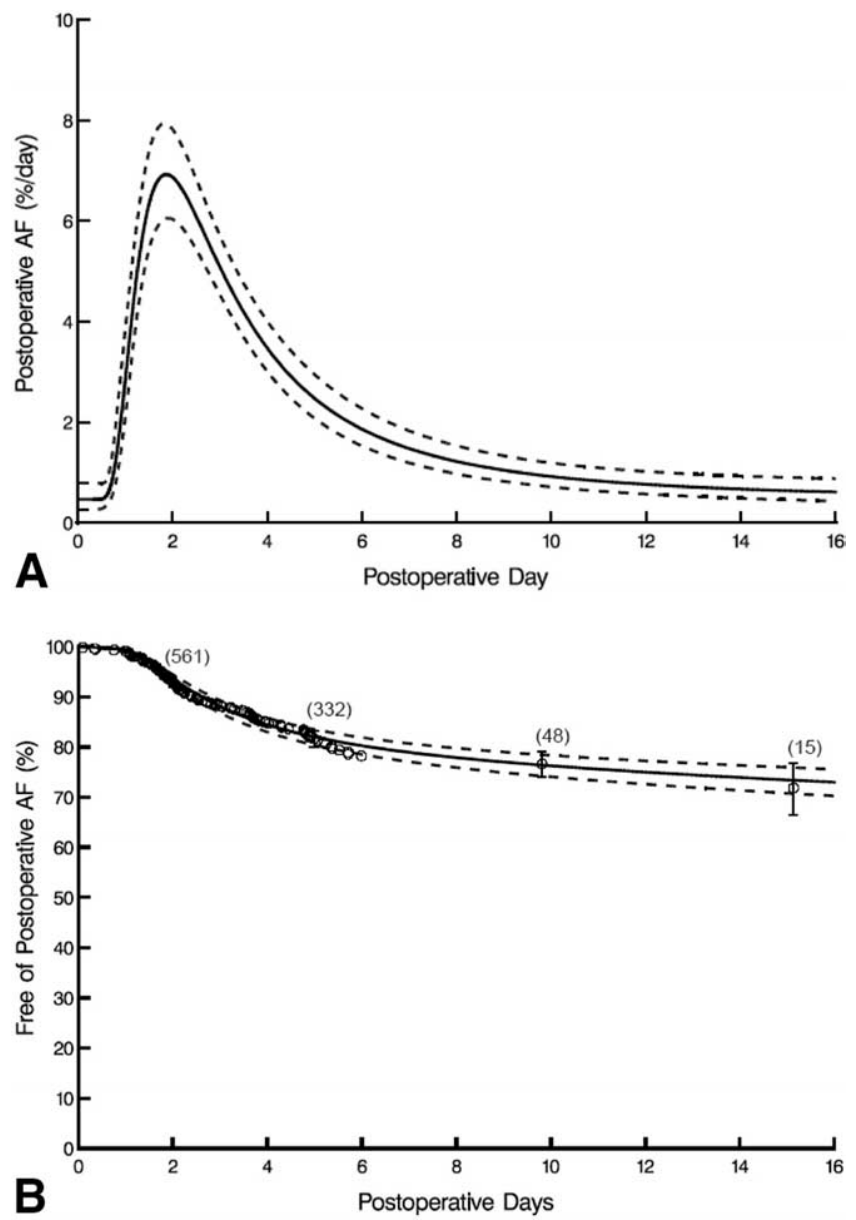

Figure 1. AF complicating lung cancer resection. A, Hazard (instantaneous risk). Solid line is parametric estimate enclosed within dashed $68 \%$ confidence limits. B, Freedom from AF. Each circle represents onset of $A F$; vertical bars are asymmetric $68 \%$ CLs, and numbers in parentheses are patients remaining at risk. Solid line is parametric estimate enclosed within dashed $68 \%$ CLs.

\section{Economics}

Economics of AF were assessed by (1) prevalence of other postoperative complications, (2) postoperative length of stay, (3) postoperative direct technical costs exclusive of operative day, and (4) in-hospital mortality. Direct technical costs include those directly associated with patient care, obtained from the hospital's meticulously detailed cost-accounting system: room, intensive care unit, nursing, pharmacy, respiratory therapy, radiology, laboratory, pain management, and miscellaneous (for details, see http://www. eclipsys.com/Solutions/executives.asp). Indirect costs and professional fees were not included.

\section{Data Analysis}

Characterization of postoperative AF. Prevalence of, timing of, and risk factors for postoperative AF were characterized in the
TABLE 2. Risk factors for postoperative AF

\begin{tabular}{|c|c|c|}
\hline Factor & Logistic coefficient $\pm \mathrm{SE}$ & $P$ value \\
\hline \multicolumn{3}{|l|}{ Demographic } \\
\hline Older* & $3.4 \pm 0.82$ & $<.0001$ \\
\hline Male & $0.65 \pm 0.25$ & .009 \\
\hline \multicolumn{3}{|l|}{ Comorbidities } \\
\hline Paroxysmal AF & $1.4 \pm 0.40$ & .0004 \\
\hline Heart failure & $1.3 \pm 0.49$ & .006 \\
\hline \multicolumn{3}{|l|}{ Procedure } \\
\hline Clamshell incision & $3.5 \pm 1.3$ & .007 \\
\hline Right pneumonectomy & $1.7 \pm 0.39$ & $<.0001$ \\
\hline Intercept & $-16.4 \pm 3.5$ & $<.0001$ \\
\hline
\end{tabular}

hazard function domain. ${ }^{16}$ Variables examined are listed in Appendix 2. Variable selection was based on bootstrap bagging with a retention criterion of $P=.05 .^{17,18}$

Temporal relation to other postoperative complications. For each other postoperative complication, the relation of its onset to that of AF was determined and is presented as a cumulative distribution.

Economics. To make a fair comparison of the impact of AF on outcome, a propensity score was developed to match patients with AF to those without. ${ }^{19,20}$ Ninety-one patient pairs were produced (Table E1). Outcome measures were compared between the two groups with the Wilcoxon rank-sum test for simple proportions (other postoperative complications and mortality), median test (postoperative length of stay), and ratio test (direct technical costs from postoperative day 1 to discharge). For the last, the cost ratio (AF group/non-AF group) of each matched pair was calculated. Confidence limits (CL) were determined from the distribution of median ratio in 10,000 bootstrap resamplings. These comparisons were repeated for the subgroup of patients with AF but without other postoperative complications and with matched pairs.

Presentation. Mean values are accompanied by $1 \mathrm{SD}$ and regression coefficients by $1 \mathrm{SE}$. Proportions and other point estimates are accompanied by asymmetric CLs equivalent to $1 \mathrm{SE}$ $(68 \%)$. We have avoided presenting logistic regression results as odds ratios because of data transformations.

\section{Results}

\section{Characterization of $\mathbf{A F}$}

AF occurred in 113 patients (19\%, CL 17\%-20\%). Patient characteristics and operative details of this group versus those without AF are given in Table 1. Risk of AF peaked on day 2 (Figure $1, A$ ); patients free of AF by postoperative day 5 seldom developed it (Figure 1,B).

Risk factors for AF included older age, male gender, paroxysmal AF, heart failure, clamshell incision, and right pneumonectomy (Table 2). Histories of paroxysmal AF and heart failure were associated with importantly increased occurrence of postoperative AF, particularly in older patients (Table 2, Figure 2). Right pneumonectomy also was 

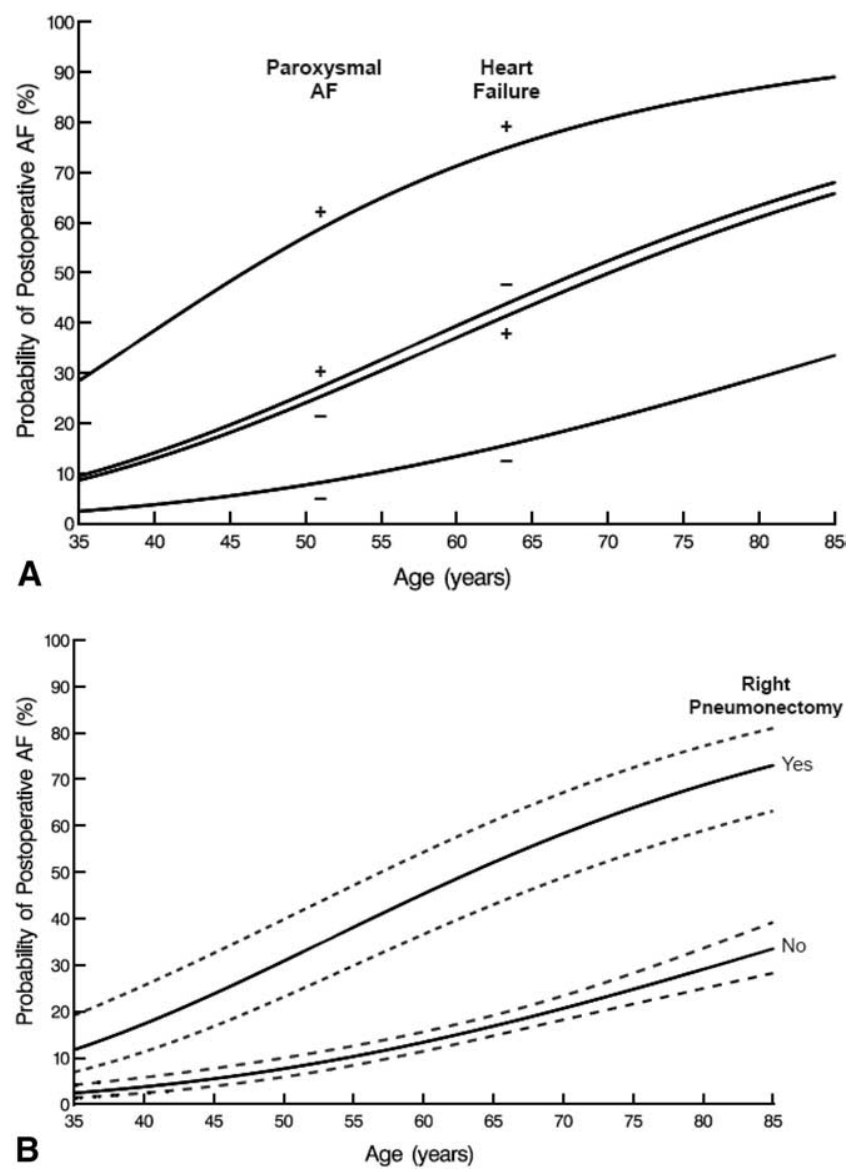

Figure 2. Risk factors for postoperative AF based on multivariable analysis (Table 2). A, Association with paroxysmal AF, heart failure, and age solved for man undergoing thoracotomy for lobectomy. Plus and minus signs indicate presence and absence of one of the two risk factors. B, Association with right pneumonectomy solved for man without paroxysmal AF or heart failure undergoing thoracotomy. Dashed lines represent $68 \%$ CLs.

associated with substantially increased occurrence of AF (Figure 2, B).

\section{Temporal Relation to Other Postoperative Complications}

Among the 113 patients who had postoperative AF, it was a solitary complication in 75 (66\%, CL 61\%-71\%). Thirtyeight (33\%, CL 29\%-39\%) had other postoperative complications, including respiratory in 30 patients, infectious in 21 , pleural in 14, renal in 5, and other cardiovascular in 14 (some patients had multiple complications). AF preceded these other complications in 14 patients (37\%, CL 28\%$46 \%$ ), coincided within 24 hours in 11 (29\%, CL $21 \%$ $38 \%$ ), and followed in 13 (34\%, CL 26\%-43\%; Figure 3).

Only $13 \%$ (CL $7 \%-22 \%$ ) of respiratory complications preceded AF, whereas 37\% (CL 27\%-47\%) coincided, and

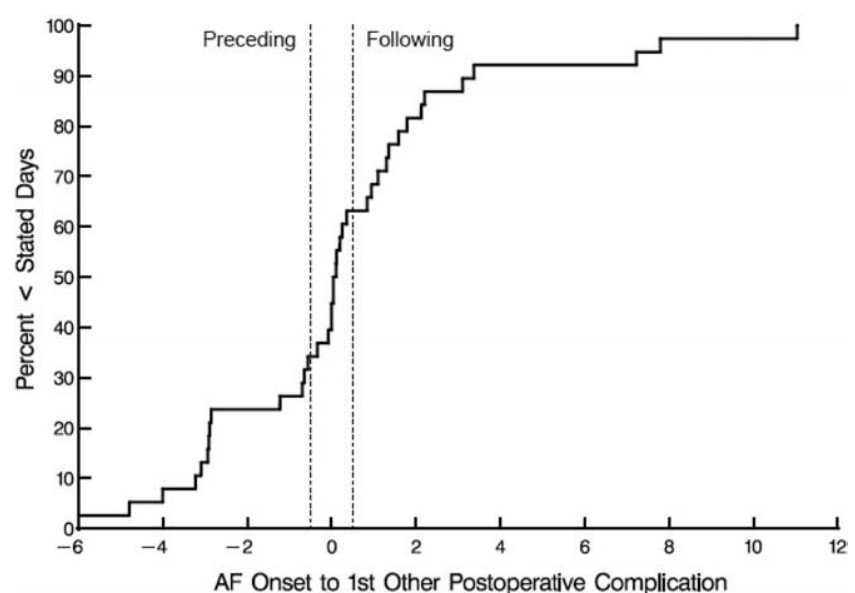

Figure 3. Temporal relation of other postoperative complications to onset (time 0 ) of postoperative AF. Cumulative distribution curve. Area between dashed lines represents coincidence of complications.

50\% (CL 39\%-60\%) followed (Figure E1, A). All infectious complications occurred either coincident with or after onset of AF, and, similar to respiratory complications, most occurred within 1 week of AF onset (Figure E1, B). Unlike these, half the pleural complications preceded onset of AF and appeared unrelated (Figure E1, C); many of these were postoperative hemothorax occurring within 24 hours of operation, much earlier than peak onset of AF. Renal failure occurred in 4 patients in the setting of multisystem organ failure and sepsis, all after onset of AF. Sixty-four percent (CL 47\%-79\%) of other cardiovascular complications followed onset of AF (Figure E1, D).

\section{Economics}

Other postoperative complications occurred in a greater proportion of propensity-matched patients who developed AF than in patients who did not $(30 \%$ vs $8.8 \%, P<.0004$; Table 3). Postoperative hospital stay was longer for patients developing postoperative AF than for those who did not (median 8 days, 15 th and 85 th percentiles 5 and 14 days, vs 5 days, 15 th and 85 th percentiles 4 and 10 days; $P<.0001$ ), and direct technical costs of postoperative care were higher (cost ratio 1.8, CL 1.6-2.1). In-hospital mortality was also higher at $8 \%(7 / 91$, CL $5 \%-11 \%)$ versus $0 \%$ (0/91, CL $0 \%-1.2 \% ; P=.01)$.

Sixty-four of the 75 patients in whom AF was a solitary complication could be propensity matched. Postoperative hospital stay was longer for these patients than for their matched counterparts who did not develop AF (median 7 days, CL 5-9 days, vs 5 days, CL 4-8 days; $P<.0001$ ), and direct technical costs of postoperative care were higher (cost ratio 1.5 , CL 1.2-1.6). 
TABLE 3. Other postoperative complications in propensity-matched patient pairs (91 pairs)

\begin{tabular}{|c|c|c|c|}
\hline Complication (No.) & Postoperative AF & No postoperative AF & $P$ value \\
\hline Respiratory & $23(25 \%)$ & $5(5.5 \%)$ & .0002 \\
\hline Respiratory distress & 16 & 5 & \\
\hline Respiratory failure & 15 & 2 & \\
\hline Pneumonia & 12 & 1 & \\
\hline Bronchopleural fistula & 1 & 0 & \\
\hline Infectious & $14(15 \%)$ & $2(2.2 \%)$ & .002 \\
\hline Sepsis & 9 & 1 & \\
\hline Pneumonia & 12 & 1 & \\
\hline Wound infection & 1 & 1 & \\
\hline Empyema & 1 & 0 & \\
\hline Pleural & $11(12 \%)$ & $2(2.2 \%)$ & .01 \\
\hline Pneumothorax & 3 & 1 & \\
\hline Hemothorax & 7 & 0 & \\
\hline Pleural effusion & 2 & 1 & \\
\hline Empyema & 1 & 0 & \\
\hline Bronchopleural fistula & 1 & 0 & \\
\hline Renal failure & $4(4.4 \%)$ & $0(0 \%)$ & .12 \\
\hline Other cardiovascular & $12(13 \%)$ & $1(1.1 \%)$ & .002 \\
\hline Myocardial infarction & 2 & 1 & \\
\hline Ventricular arrhythmia & 5 & 1 & \\
\hline Arterial thrombosis & 2 & 1 & \\
\hline Deep vein thrombosis & 5 & 0 & \\
\hline Pulmonary embolism & 1 & 0 & \\
\hline Any complication & $27(30 \%)$ & $8(8.8 \%)$ & .0004 \\
\hline
\end{tabular}

$A F$, Atrial fibrillation. ${ }^{*}$ Complications are not mutually exclusive.

\section{Discussion}

Because postoperative AF is readily managed, its importance is often unappreciated. ${ }^{6-8}$ Yet, apart from air leak, ${ }^{21}$ no single postoperative complication occurs as frequently: Every fifth patient in this study had it.

\section{Characterization of AF}

Without prophylaxis, ${ }^{14}$ prevalence of AF after pulmonary resection has ranged from $8 \%$ to $42 \%,{ }^{1-13}$ and, as in this study, peak onset is on the second postoperative day. ${ }^{4-8}$ However, differences in composition of the patient groups make comparisons among studies difficult. This is because, as expected from studies in the general population, ${ }^{22}$ older patients, men, and those with a history of previous arrhythmias and underlying heart disease have a high prevalence of postoperative AF. ${ }^{1,23}$ To these are added risk factors particular to pulmonary resection, including open versus videoassisted thoracic surgery, ${ }^{13}$ clamshell versus thoracotomy (in this study), and pneumonectomy versus lobectomy. ${ }^{4-6,8,11,12}$ Differences in prevalence of these powerful risk factors among operative experiences greatly affect occurrence of AF. ${ }^{4-6,8,12}$

\section{Temporal Relation to Other Postoperative Complications}

In two thirds of the patients, AF was a solitary complication. In the other third, however, other complications occurred, and this study uniquely identified their temporal relation to onset of AF. There was a particularly close temporal link with respiratory and infectious complications. Processes such as sepsis and hypoxia can stimulate inflammatory and autonomic responses that may trigger AF in these vulnerable patients. ${ }^{24,25}$ Thus, AF may reflect the early systemic manifestations of these serious complications.

\section{Economics}

According to our propensity-matched study, postoperative AF is a marker for a complicated, prolonged, expensive, and possibly lethal postoperative course. Because of the impossibility of a prospective study, inferences concerning the economic importance of AF vary widely. ${ }^{3,6-9,11,14}$ Recently, Vaporciyan and colleagues ${ }^{1}$ reported that postoperative AF in a large, uncontrolled experience of thoracic surgery was associated with increased length of stay, cost, and mortality. Propensity matching in our study permitted more controlled comparisons that support their findings. In addition, other complications and death occurred more often among patients who had postoperative AF. This is similar to the findings of Murthy and colleagues, ${ }^{26}$ who noted that patients with postoperative AF had more pulmonary and septic complications and higher mortality after esophagectomy than propensity-matched patients without AF. 
Of particular interest was our finding that even when $\mathrm{AF}$ was a solitary postoperative complication, length of stay, costs, and in-hospital mortality were considerably higher. This was due to the costs of managing the AF, highlighting the need for effective prophylaxis and improved management of AF.

\section{Strengths and Limitations}

A strength of this study is that it addressed a defined problem (postoperative AF monitored continuously throughout the hospital course) in a large group of patients with a single disease (non-small cell lung cancer) undergoing a single type of operation (anatomic resection) in the contemporary era. Another is the novel approach we have taken to generate valid conclusions. We have identified on a continuous time line the clinical onset of early postoperative complications, expressing these in relation to onset of AF; we have used meticulous cost-accounting data, not charges; and we have used propensity matching, which is considered to be the most valid method for making comparisons in the context of nonrandomized (in this case, nonrandomizable) studies of clinical experience.

A limitation is that it was a single-institution clinical cohort study, which restricts its generalizability. Although most patients $(81 \%)$ were matched, propensity methods of comparison are limited by inability to account for unrecorded variables. Unmatched patients included those with clamshell incisions who had complex operations that usually required chest wall or central airway resection. Because we monitored AF continuously, the period of study extended only to hospital discharge. Finally, from this clinical study it is impossible to determine the biologic mechanisms responsible for the observed associations.

\section{Recommendations}

Because postoperative AF is a solitary complication in about two thirds of the patients in whom it occurs, treatments directed at rate control and rhythm conversion are initially most important. ${ }^{5,15,27}$ These include correcting electrolyte abnormalities, intravenous calcium-channel blockers or $\beta$-blockers, and pharmacologic or electrical cardioversion for patients with recurrent or refractory $\mathrm{AF}^{5,15,27}$ Because in another third of patients it is associated with more serious complications, however, occurrence of AF should trigger a thorough workup, including physical examination, chest radiography, pulse oximetry, and white blood cell count.

\section{Conclusions}

$\mathrm{AF}$ occurs in 1 in 5 patients after lung cancer resection, with peak onset on postoperative day 2. Risk factors are both patient and procedure related, and AF may herald other serious complications. Although AF is often solitary, its occurrence is associated with longer hospital stay and higher cost. It therefore requires prompt treatment and should stimulate investigation for other problems.

\section{References}

1. Vaporciyan AA, Correa AM, Rice DC, Roth JA, Smythe WR, Swisher SG, et al. Risk factors associated with atrial fibrillation after noncardiac thoracic surgery: analysis of 2588 patients. $J$ Thorac Cardiovasc Surg. 2004;127:779-86.

2. Kim K, Rice TW, Murthy SC, DeCamp MM, Pierce CD, Karchmer DP, et al. Combined bronchoscopy, mediastinoscopy, and thoracotomy for lung cancer: who benefits? J Thorac Cardiovasc Surg. 2004; 127:850-6.

3. Harpole DH, Liptay MJ, DeCamp MM Jr, Mentzer SJ, Swanson SJ, Sugarbaker DJ. Prospective analysis of pneumonectomy: risk factors for major morbidity and cardiac dysrhythmias. Ann Thorac Surg. 1996;61:977-82.

4. von Knorring J, Lepantalo M, Lindgren L, Lindfors O. Cardiac arrhythmias and myocardial ischemia after thoracotomy for lung cancer. Ann Thorac Surg. 1992;53:642-7.

5. Ciriaco P, Mazzone P, Canneto B, Zannini P. Supraventricular arrhythmia following lung resection for non-small cell lung cancer and its treatment with amiodarone. Eur J Cardiothorac Surg. 2000;18:12-6.

6. Rena O, Papalia E, Oliaro A, Casadio C, Ruffini E, Filosso PL, et al. Supraventricular arrhythmias after resection surgery of the lung. Eur J Cardiothorac Surg. 2001;20:688-93.

7. Cardinale D, Martinoni A, Cipolla CM, Civelli M, Lamantia G, Fiorentini C, et al. Atrial fibrillation after operation for lung cancer: clinical and prognostic significance. Ann Thorac Surg. 1999;68:182731

8. Asamura H, Naruke T, Tsuchiya R, Goya T, Kondo H, Suemasu K. What are the risk factors for arrhythmias after thoracic operations? A retrospective multivariate analysis of 267 consecutive thoracic operations. J Thorac Cardiovasc Surg. 1993;106:1104-10.

9. Amar D, Roistacher N, Burt M, Reinsel RA, Ginsberg RJ, Wilson RS. Clinical and echocardiographic correlates of symptomatic tachydysrhythmias after noncardiac thoracic surgery. Chest. 1995;108:349-54.

10. Krowka MJ, Pairolero PC, Trastek VF, Payne WS, Bernatz PE. Cardiac dysrhythmia following pneumonectomy. Clinical correlates and prognostic significance. Chest. 1987;91:490-5.

11. Curtis JJ, Parker BM, McKenney CA, Wagner-Mann CC, Walls JT, Demmy TL, et al. Incidence and predictors of supraventricular dysrhythmias after pulmonary resection. Ann Thorac Surg. 1998;66:1766-71.

12. Dyszkiewicz W, Skrzypczak M. Atrial fibrillation after surgery of the lung: clinical analysis of risk factors. Eur J Cardiothorac Surg. 1998; 13:625-8.

13. Neunstein SM, Kahn P, Krellenstein DJ, Cohen E. Incidence of arrhythmias after thoracic surgery: thoracotomy versus video-assisted thoracoscopy. J Cardiothorac Vasc Anesth. 1998;12:659-61.

14. Lanza LA, Visbal AI, DeValeria PA, Zinsmeister AR, Diehl NN, Trastek VF. Low-dose oral amiodarone prophylaxis reduces atrial fibrillation after pulmonary resection. Ann Thorac Surg. 2003;75:223-30.

15. Fuster V, Ryden LE, Asinger RW, Cannom DS, Crijns HJ, Frye RL, et al. ACC/AHA/ESC guidelines for the management of patients with atrial fibrillation. A report of the American College of Cardiology/ American Heart Association Task Force on Practice Guidelines and the European Society of Cardiology Committee for Practice Guidelines and Policy Conferences (Committee to develop guidelines for the management of patients with atrial fibrillation) developed in collaboration with the North American Society of Pacing and Electrophysiology. Eur Heart J. 2001;22:1852-923.

16. Blackstone EH, Naftel DC, Turner ME Jr. The decomposition of time-varying hazard into phases, each incorporating a separate stream of concomitant information. J Am Stat Assoc. 1986;81:615-24.

17. Breiman L. Bagging predictors. Machine Learning. 1996;24:123-40.

18. Blackstone EH, Rice TW. Clinical-pathologic conference: use and choice of statistical methods for the clinical study, "superficial adenocarcinoma of the esophagus." J Thorac Cardiovasc Surg. 2001;122: 1063-76. 
19. Rosenbaum PR, Rubin DB. The central role of the propensity score in observational studies for causal effects. Biometrika. 1983;70:41-55.

20. Blackstone EH. Comparing apples and oranges. J Thorac Cardiovasc Surg. 2002;123:8-15.

21. Okereke I, Murthy SC, Alster JM, Blackstone EH, Rice TW. Characterization and importance of air leak after lobectomy. Ann Thorac Surg. 2005;79:1167-73.

22. Kannel WB, Wolf PA, Benjamin EJ, Levy D. Prevalence, incidence, prognosis, and predisposing conditions for atrial fibrillation: population-based estimates. Am J Cardiol. 1998;82:2N-9N.

23. Mathew JP, Parks R, Savino JS, Friedman AS, Koch C, Mangano DT, et al. Atrial fibrillation following coronary artery bypass graft surgery: predictors, outcomes, and resource utilization. MultiCenter Study of Perioperative Ischemia Research Group. JAMA. 1996;276:300-6.

24. Aviles RJ, Martin DO, Apperson-Hansen C, Houghtaling PL, Rautaharju $\mathrm{P}$, Kronmal RA, et al. Inflammation as a risk factor for atrial fibrillation. Circulation. 2003;108:3006-10.

25. Falk RH. Etiology and complications of atrial fibrillation: insights from pathology studies. Am J Cardiol. 1998;82:10N-7N.

26. Murthy SC, Law S, Whooley BP, Alexandrou A, Chu KM, Wong J. Atrial fibrillation after esophagectomy is a marker for postoperative morbidity and mortality. J Thorac Cardiovasc Surg. 2003;126:1162-7.

27. Barbetakis N, Vassiliadis M. Is amiodarone a safe antiarrhythmic to use in supraventricular tachyarrhythmias after lung cancer surgery? BMC Surg. 2004;4:7.

28. Arozullah AM, Khuri SF, Henderson WG, Daley J. Development and validation of a multifactorial risk index for predicting postoperative pneumonia after major noncardiac surgery. Ann Intern Med. 2001;135:847-57.

29. Bone RC, Balk RA, Cerra FB, Dellinger RP, Fein AM, Knaus WA, et al. Definitions for sepsis and organ failure and guidelines for the use of innovative therapies in sepsis. The ACCP/SCCM Consensus Conference Committee. American College of Chest Physicians/Society of Critical Care Medicine. Chest. 1992;101:1644-55.

30. Alpert JS, Thygesen K, Antman E, Bassand JP. Myocardial infarction redefined-a consensus document of The Joint European Society of Cardiology/American College of Cardiology Committee for the redefinition of myocardial infarction. J Am Coll Cardiol. 2000;36:959-69.

\section{Appendix 1: Modes of confirmation of other complications \\ Respiratory}

Respiratory distress. Increasing oxygen requirements necessitating transfer to the intensive care unit.

Respiratory failure. Mechanical ventilation after reintubation or tracheostomy.

Pneumonia. $^{28}$ (1) Rales or dullness to percussion on physical examination; (2) chest radiograph showing new infiltrate, consolidation, cavitation, or effusion; and (3) any one of the following: (a) purulent sputum, (b) isolation of organism from blood culture, or (c) isolation of pathogen from tracheal aspirate or bronchial washing.

Bronchopleural fistula. Confirmed at operation.

\section{Infectious}

All infectious diagnoses were confirmed by a staff consultant from the Department of Infectious Disease.

Sepsis. ${ }^{29}$ Presence of organ dysfunction with two or more of the following features of infection-induced systemic inflammation: (1) fever or hypothermia, (2) tachycardia, (3) tachypnea, (4) leukocytosis or leukopenia.
Pneumonia. As defined for respiratory category.

Wound infection. Drainage or cellulitis for which the wound is opened.

Empyema. Purulent chest tube drainage or thoracentesis confirmed by culture.

\section{Pleural}

Pneumothorax, hemothorax, pleural effusion. Diagnosed by chest radiography and requiring tube thoracostomy or operative drainage.

Empyema and bronchopleural fistula. As defined for infectious and respiratory categories.

\section{Renal}

Renal failure. Need for dialysis.

\section{Other Cardiovascular}

Myocardial infarction. ${ }^{30}$ Rise and fall of creatine kinase isoenzyme MB or troponin with at least one of the following: (1) symptoms, (2) Q waves on electrocardiogram, (3) electrocardiographic changes indicative of ischemia, or (4) coronary intervention.

Ventricular arrhythmias. Documented electrocardiographically, confirmed by cardiologist, and treated.

Arterial thromboembolism. Clinical scenario of ischemia requiring surgery with confirmation of thromboses at operation.

Deep venous thrombus. Diagnosed by duplex ultrasonography.

Pulmonary embolism. Diagnosed by computed tomography or pulmonary angiography.

\section{Appendix 2: Variables used in analyses \\ Demographic. Gender, age (years).}

Cardiac comorbidity. Paroxysmal AF, ventricular arrhythmia, coronary artery disease, previous myocardial infarction, percutaneous coronary intervention, atrial septal defect, mitral valve disease, heart failure, pulmonary embolism, hypertension, previous cardiac operation.

Noncardiac comorbidity. Smoking (including current, ever, quit, pack-years), previous thoracotomy, hyperthyroidism, diabetes, Eastern Cooperative Oncology Group score, American Society of Anesthesiology score.

Procedural. Bronchoscopy and mediastinoscopy before operation, approach (thoracotomy, clamshell incision, sternotomy), converted video-assisted thoracic surgery, pneumonectomy (and anatomic location), lobectomy (and anatomic location), segmentectomy (and anatomic location), wedge (and location), sleeve resection, mediastinal lymph node dissection, chest wall resection, surgeon.

Experience. Date of operation (interval in years since January 1998) 

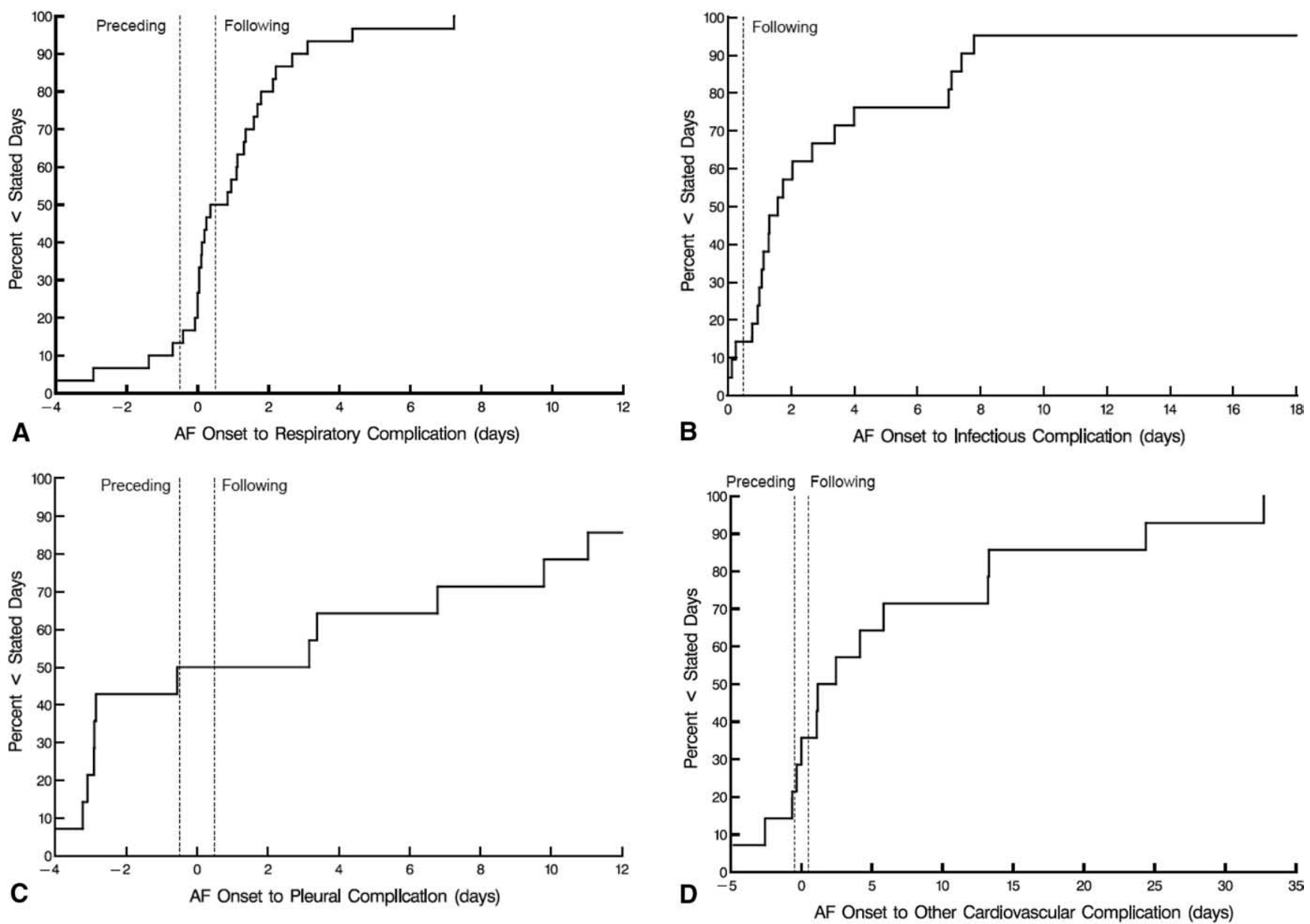

Figure E1. Temporal relation of other postoperative complications to onset (time 0 ) of postoperative AF. Cumulative distribution curves. Area between dashed lines represents coincidence of complications. A, Respiratory. B, Infectious. C, Pleural. D, Other cardiovascular. 
TABLE E1. Characteristics of propensity-matched patients ( $n=91$ for both groups)

\begin{tabular}{|c|c|c|c|}
\hline Variable & Postoperative AF & No postoperative AF & $P$ value* \\
\hline \multicolumn{4}{|l|}{ Demographic } \\
\hline Male (No.) & $66(73 \%)$ & $72(79 \%)$ & .3 \\
\hline Age $(y$, mean $\pm S D)$ & $67 \pm 8$ & $66 \pm 10$ & .4 \\
\hline \multicolumn{4}{|l|}{ Cardiovascular comorbidity (No.) } \\
\hline History of AF & $7(8 \%)$ & $8(9 \%)$ & .8 \\
\hline History of ventricular arrhythmia & $0 / 90(0 \%) \dagger$ & $1 / 89(1 \%)$ & .5 \\
\hline Coronary artery disease & $22 / 90(24 \%)$ & $25 / 90(28 \%)$ & .6 \\
\hline Mitral valve disease & $4 / 90(4 \%)$ & $4 / 89(4 \%)$ & 1.0 \\
\hline Heart failure & $3 / 90(3 \%)$ & $5 / 89(6 \%)$ & .5 \\
\hline History of pulmonary embolism & $0 / 90(0 \%)$ & $0 / 89(0 \%)$ & - \\
\hline Hypertension & $17 / 90(19 \%)$ & $21 / 89(24 \%)$ & .4 \\
\hline Previous cardiac operation & $11(12 \%)$ & $11(12 \%)$ & 1.0 \\
\hline \multicolumn{4}{|l|}{ Noncardiac comorbidity (No.) } \\
\hline Smoking & $83 / 85(96 \%)$ & $85 / 88(96 \%)$ & 1.0 \\
\hline Previous thoracotomy & $2(2 \%)$ & $0(0 \%)$ & .5 \\
\hline Hyperthyroidism & $0 / 90(0 \%)$ & $0 / 89(0 \%)$ & - \\
\hline ECOG score & & & .9 \\
\hline 0 & $39(43 \%)$ & $36(40 \%)$ & \\
\hline 1 & $42(46 \%)$ & $45(49 \%)$ & \\
\hline 2 & $10(11 \%)$ & $10(11 \%)$ & \\
\hline \multicolumn{4}{|l|}{ Procedure (No.) } \\
\hline \multicolumn{4}{|l|}{ Approach } \\
\hline Thoracotomy & $90(99 \%)$ & $90(99 \%)$ & 1.0 \\
\hline Sternotomy & $0(0 \%)$ & $0(0 \%)$ & \\
\hline Clamshell incision & $1(1 \%)$ & $1(1 \%)$ & 1.0 \\
\hline \multicolumn{4}{|l|}{ Anatomic resection } \\
\hline Pneumonectomy & $20(22 \%)$ & $16(18 \%)$ & .5 \\
\hline Right & $11(12 \%)$ & $10(11 \%)$ & .8 \\
\hline Left & $9(10 \%)$ & $6(7 \%)$ & .4 \\
\hline Intrapericardial & $2(2 \%)$ & $1(1 \%)$ & 1.0 \\
\hline Lobectomy & $64(70 \%)$ & $69(76 \%)$ & .4 \\
\hline Segmentectomy & $8(9 \%)$ & $6(7 \%)$ & .6 \\
\hline \multicolumn{4}{|l|}{ Additional procedures (No.) } \\
\hline Wedge resection & $5(5 \%)$ & $4(4 \%)$ & 1.0 \\
\hline Sleeve resection & $3(3 \%)$ & $4(4 \%)$ & 1.0 \\
\hline Mediastinal lymph node dissection & $45(49 \%)$ & $42(46 \%)$ & .7 \\
\hline Chest wall resection & $3(3 \%)$ & $5(5 \%)$ & .7 \\
\hline
\end{tabular}

$A F$, Atrial fibrillation; ECOG, Eastern Cooperative Oncology Group; SD, standard deviation. *Test of difference between AF and no-AF groups, Fisher's exact test used where appropriate. †Denominator represents number of patients without missing data. 